\title{
Inflation Target Shocks and Monetary Policy Inertia in the Euro Area
}

\author{
Patrick Fève ${ }^{\mathrm{a}, \mathrm{b} *}$, Julien Matheron ${ }^{\mathrm{b}, \mathrm{c}}$, Jean-Guillaume Sahuc ${ }^{\mathrm{b}, \mathrm{d}}$ \\ ${ }^{\mathrm{a}}$ Toulouse School of Economics (GREMAQ and IDEI) \\ ${ }^{\mathrm{b}}$ Banque de France, Research Department \\ ${ }^{\mathrm{c}}$ SDFi (University of Paris-Dauphine) \\ $\mathrm{d}$ Audencia School of Management
}

June 6, 2008

\begin{abstract}
The euro area as a whole has experienced a marked downward trend in inflation over the past decades and, concomitantly, a protracted period of depressed activity. Can permanent shifts in monetary policy be held responsible for these dynamics? To answer this question, we embed serially correlated changes in the inflation target into a DSGE model with real and nominal frictions. The formal Bayesian estimation of the model suggests that gradual changes in the inflation target have played a major role in the euro area business cycle. Following an inflation target shock, the real interest rate increases sharply and persistently, leading to a protracted decline in economic activity. Counter-factual exercises show that, had monetary policy implemented its new inflation objective at a faster rate, the euro zone would have experienced more sustained growth than it actually did.

Keywords: Permanent inflation target shocks, Monetary policy inertia, DSGE models, Bayesian econometrics
\end{abstract}

JEL Class.: E31, E32, E52

\footnotetext{
*Address: Université de Toulouse 1, Aile Jean-Jacques Laffont, 21 Allée de Brienne, 31000, Toulouse, France. email: patrick.feve@univ-tlse1.fr. We thank F. Collard for insightful comments on an earlier draft. The views expressed herein are those of the authors and should not be interpreted as reflecting those of the Banque de France.
} 


\section{Introduction}

Inflation in the euro area fell dramatically from $12 \%$ in the early 1980 's to $4 \%$ in the early 1990 's. In spite of some differences, inflation rates in most member countries display a significant downward trend over this period. These dynamics have followed purposeful monetary policies aimed at stabilizing inflation to lower levels (e.g., Germany in the early eighties, or the competitive disinflation in France, in the mid eighties). At the very same time, these economies experienced protracted periods of recessions. Of course, the dynamics of macroeconomic variables might be due to other factors or shocks than monetary policy. However, a legitimate question is to assess whether permanent changes in monetary policy have significantly affected these dynamics over the past decades. If so, through which channels did these shocks propagate?

To investigate quantitatively these issues, we summarize the complex process of disinflation policies in the euro area by permanent and gradual changes in the time varying inflation target of the stand-in European Central Bank. This inflation target is further embedded in a Dynamic Stochastic General Equilibrium (DSGE) model, imposing the Friedmanian premise that low frequency movements in inflation, if any, are necessarily due to this feature of monetary policy. ${ }^{1}$

The main model features are the following. First and foremost, as in Ireland (2007), we assume that the inflation target follows a non-stationary process. In contrast with Ireland, though, we assume that changes in the inflation target are exogenous and serially correlated. This is meant to capture the complex and heterogeneous processes of disinflation policies in euro area countries taken as a whole. Second, the DSGE model allows for various real and nominal frictions, such as habits in consumption, sticky prices, and sticky wages. ${ }^{2}$ In the case of euro area data, gradual inflation target shocks and wage stickiness can be potentially crucial. Indeed, as argued by Blanchard (2003), two suspects for the protracted period of depressed economic activity in Europe over the eighties are: (i) excessive and persistent real wages and (ii) persistently high real interest rates. Allowing for sticky wages helps us quantify the importance of the first suspect. Considering gradual inflation target shocks can also help rationalize the observed inertial dynamics of the short term nominal interest rate which remained above inflation for a very long period in the eighties and nineties.

\footnotetext{
${ }^{1} \mathrm{~A}$ number of recent papers have adopted time varying inflation targets in DSGE models. See, among others, Adolfson et al. (2005, 2007), Cogley and Sbordone (2007), Erceg and Levin (2003), Ireland (2007), Melecky et al. (2008), Smets and Wouters (2005), and de Walque et al. (2007).

${ }^{2}$ Our setup also incorporates material goods and a production function à la Kimball (1995).
} 
In disentangling the respective roles of each suspect and the channels through which they contributed to propagate inflation target shocks, a formal econometric procedure is required. In this paper, the DSGE model is taken to the data by adopting a full system Bayesian estimation procedure. Using marginal likelihoods and posterior odds provides appropriate inputs for models comparison. This will prove particularly useful when assessing the importance of our assumption of gradual permanent inflation target shocks.

Our main results are the following. First, we find that inflation target shocks significantly contributed to aggregate fluctuations in the euro area. This result crucially depends on our assumption of gradual diffusion for these shocks. Ignoring this feature, these shocks are no longer essential in explaining fluctuations of real variables. At the same time, our hypothesis is strongly supported by the data. Indeed, a version of our model without gradual inflation target shocks has a much lower marginal likelihood than our benchmark model. Inspecting the impulse response functions, we also find that the real wage actually declines after an inflation target shock while the real interest rate persistently increases. This suggests that the main suspect accounting for the recessionary effects of disinflation shocks is the inertial behavior of monetary policy, in the form of both gradual disinflation shocks and an inertial interest rate rule.

These results are confirmed by a series of counterfactual exercises conducted with our estimated DSGE model. We find that, absent inflation target shocks, output would have been much higher over the eighties than it actually was. This is a direct consequence of the high and persistent increase of the real interest rate triggered by negative inflation target shocks that would have otherwise been avoided. In addition, we perturb the parameters governing inertia and gradualism in monetary policy. We find that both stories have played a central role in propagating these shocks. These two features turn out to imply very long lasting increases in the real interest rate, translating into persistent output losses. Had monetary policy implemented its new inflation objective at a faster rate, the euro zone would have experienced more sustained growth than it actually did during the eighties.

The paper is organized as follows. A first section expounds our theoretical model in detail. Section 2 lays out our econometric procedure and comments on the estimation results. Counterfactual experiments are conducted in section 3. The last section offers concluding remarks. 


\section{The DSGE Model}

We consider a discrete time economy, populated with a continuum of infinitely-lived households indexed by $v \in[0,1]$. Households are endowed with specific skills that are combined together in an aggregate labor index by an employment agency, as in Erceg et al. (2000). Perfectly competitive firms produce an aggregate good that can be either consumed or used as a production input. The aggregate good is produced by combining imperfectly substitutable intermediate goods, each of which is produced by monopolistic firms which combine aggregate labor and material goods according to a Leontief production function. These firms face random nominal price reoptimization opportunities, according to the Calvo (1983) specification. Symmetrically, households reoptimize their nominal wage at random intervals. We now expound our model in deeper detail.

\subsection{Households and Wage Setting}

The typical household $v$ seeks to maximize

$$
\mathrm{E}_{t} \sum_{T=t}^{\infty} \beta^{T}\left\{\mathrm{e}^{g_{T}} \log \left(c_{T}-\bar{b} c_{T-1}\right)-V\left(h_{T}(v)\right\},\right.
$$

where $\beta \in[0,1)$ is the subjective discount factor, $\bar{b} \in(0,1)$ is the degree of habit formation in consumption, $c_{t}$ is consumption, $h_{T}(v)$ is the supply of labor of type $v$, and $V\left(h_{T}(v)\right)$ is the associated disutility. Finally, $g_{t}$ is a consumption-preference shock, the dynamics of which will be specified later. The household faces the sequence of constraints

$$
P_{T} c_{T}+B_{T+1} / R_{T}=W_{T}(v) h_{T}(v)+\operatorname{Prof}_{T}+B_{T},
$$

where $P_{t}$ is the aggregate price level, $B_{t+1}$ is the quantity of nominal government bonds acquired at $t$, maturing at $t+1$, and paying the gross nominal interest rate $R_{t} . W_{t}(v)$ is the nominal wage paid to labor of type $v$. Finally Prof $_{t}$ denotes profits redistributed by monopolistic firms.

Each household supplies labor to a competitive employment agency which combines the differentiated labor inputs $\left\{h_{t}(v), v \in[0,1]\right\}$ into an aggregate labor index $h_{t}$ according to

$$
h_{t}=\left(\int_{0}^{1} h_{t}(v)^{\left(\theta_{w, t}-1\right) / \theta_{w, t}} \mathrm{~d} v\right)^{\theta_{w, t} /\left(\theta_{w, t}-1\right)},
$$

where $\theta_{w, t}>1$ is the stochastically varying elasticity of substitution between any two labor types, the dynamics of which will be specified later. Associated with this technology is the demand for 
labor of type $v$, which obeys

$$
h_{t}(v)=\left(\frac{W_{t}(v)}{W_{t}}\right)^{-\theta_{w, t}} h_{t}
$$

where the aggregate wage index $W_{t}$ is defined by

$$
W_{t}=\left(\int_{0}^{1} W_{t}(v)^{1-\theta_{w, t}}\right)^{1 /\left(1-\theta_{w, t}\right)} .
$$

It is assumed that at each point in time, a typical household can reoptimize its wage with probability $1-\alpha_{w}$, irrespective of the elapsed time since it last revised its age. The remaining households simply revise their wage according to the rule

$$
W_{t}(v)=\gamma\left(\pi_{t}^{\star}\right)^{1-\gamma_{w}}\left(\pi_{t-1}\right)^{\gamma_{w}} W_{t-1}(v),
$$

where $\gamma$ is the steady state gross growth rate of technical progress, $\gamma_{w} \in[0,1]$ is the degree of indexation to the most recently available inflation measure, $\pi_{t}^{\star}$ is the gross inflation target (to be defined later), and $\pi_{t}$ is gross inflation.

Let us now turn our attention to the wage setting decision and define $h_{t, T}^{\star}(v)$ the supply of hours at $T$ by household $v$ if it last reoptimized its wage at $t$. In period $t$, if drawn to reoptimize, household $v$ chooses his wage rate $W_{t}^{\star}(v)$ so as to solve

$$
\max _{W_{t}^{\star}(v)} \mathrm{E}_{t} \sum_{T=t}^{\infty}\left(\beta \alpha_{w}\right)^{T-t}\left\{\lambda_{T} \frac{\gamma^{T-t} \delta_{t, T}^{w} W_{t}^{\star}(v)}{P_{T}}-V\left(h_{t, T}^{\star}(v)\right)\right\},
$$

subject to

$$
h_{t, T}^{\star}(v)=\left(\frac{\gamma^{T-t} \delta_{t, T}^{w}}{\pi_{t, T}^{w}} \frac{w_{t}^{\star}(v)}{w_{t}}\right)^{-\theta_{w, t}} h_{t},
$$

where $w_{t}^{\star}(v) \equiv W_{t}^{\star}(v) / P_{t}, \pi_{t, T}^{w} \equiv W_{T} / W_{t}$, and the factor $\delta_{t, T}^{w}$ obeys

$$
\delta_{t, T}^{w}=\left\{\begin{array}{ll}
\prod_{j=t}^{T-1}\left(\pi_{j+1}^{\star}\right)^{1-\gamma_{w}}\left(\pi_{j}\right)^{\gamma_{w}} & \text { if } T>t \\
1 & \text { otherwise }
\end{array},\right.
$$

For later reference, it is convenient to define the "wage markup"

$$
\mu_{w, t} \equiv \frac{\theta_{w, t}}{\theta_{w, t}-1}
$$




\subsection{Production Side and Price Setting}

There is a unique aggregate good, $d_{t}$, which can be either consumed, $y_{t}$, or used as an input in production, $x_{t}$. Thus, $d_{t}=y_{t}+x_{t}$. The aggregate good is produced by competitive firms according to the Kimball (1995) type technology

$$
\int_{0}^{1} G\left(\frac{d_{t}(\varsigma)}{d_{t}} ; \mathrm{e}^{\varphi_{t}}\right) \mathrm{d} \varsigma=1
$$

where $\varphi_{t}$ is a price-elasticity shock, the dynamics of which will be specified later, $G\left(\cdot ; \mathrm{e}^{\varphi_{t}}\right)$ is increasing and strictly concave, is such that $G_{12}(1 ; 1)=0$, and satisfies the normalization $G\left(1, \mathrm{e}^{\varphi_{t}}\right)=1$, and $d_{t}(\varsigma)$ is the input of intermediate good $\varsigma$, with $\varsigma \in[0,1] .{ }^{3}$ The Kimball (1995) type technology is a theoretical device that allows for a small slope of the Phillips curve without assuming too high a degree of nominal price rigiditiy (see, e.g., Woodford, 2003).

The associated demand function for good $\varsigma$ is

$$
d_{t}(\varsigma)=d_{t}\left(G_{1}\right)^{-1}\left(\frac{P_{t}(\varsigma)}{P_{t}} \Upsilon_{t} ; \mathrm{e}^{\varphi_{t}}\right), \quad \text { where } \Upsilon_{t} \equiv \int_{0}^{1} \frac{d_{t}(\varsigma)}{d_{t}} G_{1}\left(\frac{d_{t}(\varsigma)}{d_{t}} ; \mathrm{e}^{\varphi_{t}}\right) \mathrm{d} \varsigma .
$$

$P_{t}(\varsigma)$ is the nominal price of good $\varsigma$ and $P_{t}$ is the aggregate price level, which is implicitly defined by the relation

$$
\int_{0}^{1} \frac{P_{t}(\varsigma) d_{t}(\varsigma)}{P_{t} d_{t}} \mathrm{~d} \varsigma=1
$$

Associated with the above technology is $\theta_{p}\left(e_{t}(\varsigma), \mathrm{e}^{\varphi_{t}}\right)$ the elasticity of demand for a given intermediate good whose relative demand is equal to $e_{t}(\varsigma)$. Formally

$$
\theta_{p}\left(e_{t}(\varsigma), \mathrm{e}^{\varphi_{t}}\right)=-\frac{G_{1}\left(e_{t}(\varsigma) ; \mathrm{e}^{\varphi_{t}}\right)}{e_{t}(\varsigma) G_{11}\left(e_{t}(\varsigma) ; \mathrm{e}^{\varphi_{t}}\right)}
$$

From this, we can also define the price markup $\mu_{p}\left(e_{t}(\varsigma) ; \mathrm{e}^{\varphi_{t}}\right)$ through the familiar expression

$$
\mu_{p}\left(e_{t}(\varsigma) ; \mathrm{e}^{\varphi_{t}}\right)=\frac{\theta_{p}\left(e_{t}(\varsigma) ; \mathrm{e}^{\varphi_{t}}\right)}{\theta_{p}\left(e_{t}(\varsigma) ; \mathrm{e}^{\varphi_{t}}\right)-1}
$$

For later reference, it is also convenient to define $\mu_{p} \equiv \mu_{p}(1 ; 1)$ the steady state markup as well as

$$
\hat{\mu}_{p, t} \equiv \frac{D_{2} \mu_{p}(1 ; 1)}{\mu_{p}} \varphi_{t}
$$

\footnotetext{
${ }^{3}$ Here and in the remainder, $G_{i}$ is the partial derivative of $G$ with respect to its $i$ th argument and $G_{i j}$ is the cross partial derivative of $G$ with respect to arguments $i$ and $j$. Similarly, $\left(G_{i}\right)^{-1}$ will denote the reciprocal of $G_{i}$, taken as a function of its first argument.
} 
where $D_{2} \mu_{p}(1 ; 1) / \mu_{p}$ is the steady state elasticity of $\mu_{p}$ with respect to $\mathrm{e}^{\varphi_{t}}$, and where a hat denotes logdeviation from steady state.

Each intermediate good $\varsigma \in[0,1]$ is produced by a monopolistic firm with the same index. Firm $\varsigma$ has technology

$$
d_{t}(\varsigma)=\min \left\{\frac{\mathrm{e}^{z_{t}} n_{t}(\varsigma)-\kappa \mathrm{e}^{z_{t}}}{1-s_{x}}, \frac{x_{t}(\varsigma)}{s_{x}}\right\}
$$

where $n_{t}(\varsigma)$ and $x_{t}(\varsigma)$ are the inputs of aggregate labor and material goods, respectively, and $z_{t}$ is a permanent productivity shock, evolving according to

$$
\Delta z_{t}=\left(1-\rho_{z}\right) \gamma+\rho_{z} \Delta z_{t-1}+\sigma_{z} \epsilon_{z, t}, \quad \epsilon_{z, t} \sim N(0,1)
$$

Here, $\kappa \mathrm{e}^{z_{t}}$ is a fixed production cost which grows at the same rate as technical progress. This assumption ensures the existence of a well-defined balanced growth path. The fixed cost will be pinned down so that aggregate profits are zero in the deterministic steady state. The real marginal cost associated with the above technology is

$$
s_{t}=\left(1-s_{x}\right) w_{t} \mathrm{e}^{-z_{t}}+s_{x}
$$

where $w_{t} \equiv W_{t} / P_{t}$ is the real wage rate paid to aggregate labor.

We assume that in each period of time, a monopolistic firm can reoptimize its price with probability $1-\alpha_{p}$, irrespective of the elapsed time since it last revised its price. If the firm cannot reoptimize its price, the latter is rescaled according to the simple revision rule

$$
P_{t}(\varsigma)=\left(\pi_{t}^{\star}\right)^{1-\gamma_{p}}\left(\pi_{t-1}\right)^{\gamma_{p}} P_{t-1}(\varsigma)
$$

where $\gamma_{p} \in[0,1]$ measures the degree of indexation to the most recently available inflation measure. Let $d_{t, T}^{\star}(\varsigma)$ denote the production of firm $\varsigma$ at $T$ if it last revised its price in period $t$. Then, if drawn to reoptimize at $t$, firm $\varsigma$ sets its new price $P_{t}^{\star}(\varsigma)$ so as to solve

$$
\max _{P_{t}^{\star}(\varsigma)} \mathrm{E}_{t} \sum_{T=t}^{\infty}\left(\beta \alpha_{p}\right)^{T-t} \frac{\lambda_{T}}{\lambda_{t}}\left\{\frac{\delta_{t, T}^{p} P_{t}^{\star}(\varsigma)}{P_{t}} d_{t, T}^{\star}(\varsigma)-s_{T} d_{t, T}^{\star}(\varsigma),\right\},
$$

subject to

$$
d_{t, T}^{\star}(\varsigma)=d_{T}\left(G_{1}\right)^{-1}\left(\frac{\delta_{t, T}^{p} P_{t}^{\star}(\varsigma)}{P_{t}} \Upsilon_{T} ; \mathrm{e}^{\varphi_{T}}\right),
$$


where

$$
\delta_{t, T}^{p}= \begin{cases}\prod_{j=t}^{T-1}\left(\pi_{j+1}^{\star}\right)^{1-\gamma_{p}}\left(\pi_{j}\right)^{\gamma_{p}} & \text { if } T>t \\ 1 & \text { otherwise }\end{cases}
$$

\subsection{Monetary Policy}

The central bank is assumed to set the gross nominal interest rate $R_{t}$ according to a generalized Taylor rule. Let $\hat{R}_{t}, \hat{\pi}_{t}$, and $\hat{\pi}_{t}^{\star}$ denote the logarithms of the gross nominal interest rate, the gross inflation rate, and the gross inflation target, respectively, and let $\hat{\gamma}_{y, t}$ denote the logdeviation of the gross growth rate of aggregate output. Then, the assumed target nominal interest rate $\hat{R}_{t}^{\star}$ is

$$
\hat{R}_{t}^{\star}=\hat{\pi}_{t}^{\star}+a_{p}\left(\hat{\pi}_{t}-\hat{\pi}_{t}^{\star}\right)+a_{y} \hat{\gamma}_{y, t}
$$

This equation corresponds to a Taylor-type rule, augmented with a time-varying inflation target. Here, $a_{p}$ is the coefficient coding the responsiveness of $\hat{R}_{t}^{\star}$ to the inflation gap $\tilde{\pi}_{t} \equiv \hat{\pi}_{t}-\hat{\pi}_{t}^{\star}$. As in Coenen et al. (2008), Edge et al. (2007), and Laforte (2007), $a_{y}$ is the degree of responsiveness to the deviations of output growth from its steady state value. The inflation target itself is assumed to evolve according to

$$
\Delta \hat{\pi}_{t}^{\star}=\rho_{\pi} \Delta \hat{\pi}_{t-1}^{\star}+\sigma_{\pi} \epsilon_{\pi, t} \quad \epsilon_{\pi, t} \sim N(0,1),
$$

where $\Delta$ denotes the first difference operator. Thus, in an attempt to capture the possibly gradual shifts in the inflation target, we assume that changes in the inflation target are serially correlated. The autocorrelation coefficient $\rho_{\pi}$ reflects the slow pace at which the stand-in European Central Bank allegedly adjusted its inflation target. This is the key difference between our specification and previous works that allowed for a time varying inflation target. Either the latter is assumed to be stationary (in which case, it is undistinguishable from a standard monetary policy shock), or it is assumed to follow a random walk, as in Ireland (2007), for example.

To account for what is left of monetary policy inertia, the target nominal interest rate $\hat{R}_{t}^{\star}$ is embedded in a partial adjustment model with autocorrelated shocks, so that $\hat{R}_{t}$ and $\hat{R}_{t}^{\star}$ are linked together through the relation

$$
\hat{R}_{t}=\rho \hat{R}_{t-1}+(1-\rho) \hat{R}_{t}^{\star}+\eta_{R, t}
$$


Here, $\rho$ is the degree of interest rate smoothing; $\eta_{R, t}$ is a stationary monetary policy shock, which is assumed to evolve according to

$$
\eta_{R, t}=\rho_{R} \eta_{R, t-1}+\sigma_{R} \epsilon_{R, t}, \quad \epsilon_{R, t} \sim N(0,1) .
$$

We are a priori agnostic as to which feature of monetary policy (or combination thereof) accounts for its observed inertia. We leave it to the data to settle this question.

Before proceeding, it is important to notice that our inflation target shock is exogenous. This specification precludes the study of what has been called the "opportunistic approach " to disinflation policy. Following Ireland (2007), this opportunistic approach could have been modelled by allowing the inflation target shock to covary with supply shocks. For example, a simple specification would be

$$
\Delta \pi_{t}^{\star}=\rho \pi \Delta \pi_{t-1}^{\star}+\sigma_{\pi} \epsilon_{\pi, t}-\phi_{z} \epsilon_{z, t}+\phi_{w} \epsilon_{w, t}+\phi_{p} \epsilon_{p, t}
$$

where the response coefficients $\phi_{i} \geq 0$ for $i=\{z, w, p\}$. These parameters could be interpreted as chosen by the central bank in an attempt to permanently reduce inflation by exploiting negative cost push shocks or positive technological innovations. In our framework, as in Ireland (2007), this approach raises an econometric problem. When we estimate the model with this specification, we obtain the exact same fit as in the model with exogenous inflation target. This suggests that the two views cannot be discriminated using our data sample. This finding echoes identification issues with Taylor rules highlighted by Cochrane (2007). When we allow for an opportunistic approach to disinflation, we obtain a mechanically smaller contribution of the exogenous inflation target shocks to aggregate fluctuations, but all the endogenous propagation mechanisms associated to changes in the inflation target (either endogenous or exogenous) remain unaffected. Since our main focus is on these transmission mechanisms, we impose an exogenous inflation target in the remainder of this paper. This assumption corresponds to a Friedmanian view of the low frequency movements in inflation.

\subsection{Loglinear System}

Before loglinearizing the equilibrium conditions implied by the above model, we must appropriately get rid of the stochastic trends included in our specification. To do so, all real trending variables are 
divided by $\mathrm{e}^{z_{t}}$, while $\pi_{t}, \pi_{w, t} \equiv W_{t} / W_{t-1}$, and $R_{t}$ are divided by $\pi_{t}^{\star}$. At this stage, it is convenient to define

$$
\pi_{w, t}^{s} \equiv \pi_{w, t} / \pi_{t}^{\star}, \quad \pi_{t}^{s} \equiv \pi_{t} / \pi_{t}^{\star}, \quad R_{t}^{s} \equiv R_{t} / \pi_{t}^{\star}
$$

Similarly, we define

$$
y_{t}^{s} \equiv y_{t} / \mathrm{e}^{z_{t}}, \quad w_{t}^{s} \equiv w_{t} / \mathrm{e}^{z_{t}}, \quad \lambda_{t}^{s} \equiv \lambda \mathrm{e}^{z_{t}} .
$$

This yields the loglinear system

$$
\begin{aligned}
& \hat{\pi}_{t}^{s}-\gamma_{p} \hat{\pi}_{t-1}^{s}=\kappa_{p}\left(1-\mu_{p} s_{x}\right) \hat{w}_{t}^{s}+\beta \mathrm{E}_{t}\left\{\hat{\pi}_{t+1}^{s}-\gamma_{p} \hat{\pi}_{t}^{s}\right\}+\gamma_{p} \zeta_{t}+\tilde{\mu}_{p, t}, \\
& \hat{\pi}_{w, t}^{s}-\gamma_{w} \hat{\pi}_{t-1}^{s}=\kappa_{w}\left(\omega \tilde{\mu}_{p}^{-1} \hat{y}_{t}^{s}-\hat{\lambda}_{t}^{s}-\hat{w}_{t}^{s}\right)+\beta \mathrm{E}_{t}\left\{\hat{\pi}_{w, t+1}^{s}-\gamma_{w} \hat{\pi}_{t}^{s}\right\}+\gamma_{w} \zeta_{t}+\tilde{\mu}_{w, t}, \\
& (1-\beta b)(1-b) \hat{\lambda}_{t}^{s}=\beta b \mathrm{E}_{t}\left\{\hat{y}_{t+1}^{s}-b \hat{y}_{t}^{s}\right\}-\left(\hat{y}_{t}^{s}-b \hat{y}_{t-1}^{s}\right)+b\left[\beta \mathrm{E}_{t}\left\{\Delta z_{t+1}\right\}-\Delta z_{t}\right]+\tilde{g}_{t}, \\
& \hat{\lambda}_{t}^{s}=\hat{R}_{t}^{s}+\mathrm{E}_{t}\left\{\hat{\lambda}_{t+1}^{s}-\Delta z_{t+1}-\hat{\pi}_{t+1}^{s}-\Delta \hat{\pi}_{t+1}^{\star}\right\} \\
& \hat{R}_{t}^{s}=\rho \hat{R}_{t-1}^{s}+(1-\rho)\left[a_{p} \hat{\pi}_{t}^{s}+a_{y} \hat{\gamma}_{y, t}\right]-\rho \Delta \hat{\pi}_{t}^{\star}+\epsilon_{R, t}, \\
& \hat{\pi}_{w, t}^{s}=\hat{\pi}_{t}^{s}+\hat{w}_{t}^{s}-\hat{w}_{t-1}^{s}+\Delta z_{t}, \\
& \hat{\gamma}_{y, t}=\hat{y}_{t}^{s}-\hat{y}_{t-1}^{s}+\Delta z_{t}, \\
& \zeta_{t}=\beta \mathrm{E}_{t}\left\{\Delta \hat{\pi}_{t+1}^{\star}\right\}-\Delta \hat{\pi}_{t}^{\star} .
\end{aligned}
$$

Equations (4) and (5) are stationary versions of the New Phillips curves on prices and wages. Equations (6) and (7) define the intertemporal allocation of detrended consumption. Equation (8) corresponds to the stationary version of the generalized Taylor rule. Finally, the last three equations are simple identities.

In the system (4)-(11), we defined the auxiliary parameters

$b \equiv \bar{b} / \gamma, \quad \kappa_{w} \equiv \frac{\left(1-\beta \alpha_{w}\right)\left(1-\alpha_{w}\right)}{\left(1+\omega \theta_{w}\right) \alpha_{w}}, \quad \kappa_{p} \equiv \frac{\left(1-\beta \alpha_{p}\right)\left(1-\alpha_{p}\right)}{\alpha_{p}\left(1+\epsilon_{\mu} \theta_{p}\right)}, \quad \epsilon_{\mu} \equiv \frac{D_{1} \mu_{p}(1 ; 1)}{\mu_{p}}, \quad \tilde{\mu}_{p} \equiv \frac{\mu_{p}\left(1-s_{x}\right)}{1-\mu_{p} s_{x}}$.

Finally, the stochastic shocks $\tilde{g}_{t}, \tilde{\mu}_{p, t}$, and $\tilde{\mu}_{w, t}$ are defined in terms of the structural shocks $g_{t}, \varphi_{t}$ and $\theta_{w, t}$ according to the formulas

$$
\tilde{g}_{t}=(1-b)\left[g_{t}-\beta b \mathrm{E}_{t}\left\{g_{t+1}\right\}\right], \quad \tilde{\mu}_{p, t}=\kappa_{p} \hat{\mu}_{p, t}, \quad \tilde{\mu}_{w, t}=\kappa_{w} \hat{\mu}_{w, t} .
$$


In turn, these auxiliary shocks are assumed to evolve according to $\mathrm{AR}(1)$ processes

$$
\begin{aligned}
& \tilde{g}_{t}=\rho_{g} \tilde{g}_{t-1}+\sigma_{g} \epsilon_{g, t}, \\
& \tilde{\mu}_{p, t}=\rho_{p} \tilde{\mu}_{p, t-1}+\sigma_{p} \epsilon_{p, t}, \\
& \tilde{\mu}_{w, t}=\rho_{w} \tilde{\mu}_{w, t-1}+\sigma_{w} \epsilon_{w, t},
\end{aligned}
$$

where $\epsilon_{i, t} \sim N(0,1), \sigma_{i}>0$, and $\rho_{i} \in[0,1)$ for $i \in\{g, p, w\}$. Together with equations (1)-(3), equations (12)-(14) completely describes the assumed stochastic structure of the DSGE model.

\section{Estimation Results}

In this section, our formal econometric procedure is expounded. We then discuss our results and detail various analyses designed to understand the transmission mechanisms of permanent inflation target shocks.

\subsection{Data and Econometric Approach}

The data used in our empirical analysis are extracted from the AWM database compiled by Fagan et al. (2005). These are area-wide data for the euro zone as a whole and cover the period 1970(1)2004(4). The raw series used are the logarithm of per capita GDP, $\hat{y}_{t}$, the growth rate of the Harmonized Index of Consumer Prices, $\hat{\pi}_{t}$, the growth rate of nominal wages, $\hat{\pi}_{w, t}$, and the real ex-post interest rate (i.e. the difference between the short-term nominal interest rate and inflation), $\hat{R}_{t}-\hat{\pi}_{t} \cdot{ }^{4}$ The data are reported in figure 1 . The shaded area corresponds to the large recession period that European countries experienced during the eighties. During the same period, notice that inflation and wage inflation sharply declined. At the same time, the real (ex-post) interest rate dramatically increased in a protracted fashion. Our main goal is now to investigate whether inflation target shocks can be held responsible for these dynamic patterns. To answer this question, a formal econometric approach is required.

Let $X_{T} \equiv\left\{x_{t}\right\}_{t=0}^{T}$ denote the sample of observable (demeaned) data, where $x_{t}=\left(\Delta \hat{y}_{t}, \Delta \hat{\pi}_{t}, \Delta \hat{\pi}_{w, t}, \hat{R}_{t}-\right.$ $\left.\hat{\pi}_{t}\right)^{\prime}$. Notice that the specification of observable data in $X_{t}$ is compatible with the structural model.

\footnotetext{
${ }^{4}$ The population series used to express output in per capita terms is the working age population from various issues of OECD's Economic Perspective.
} 
Conditional on a given model specification $\mathscr{M}_{i}$, the prior distribution for the vector of model's parameters $\theta$ is $p\left(\theta \mid \mathscr{M}_{i}\right)$ and the likelihood function associated to the observable variables is $L\left(X_{T} \mid \theta, \mathscr{M}_{i}\right)$. Then, from Bayes theorem, the posterior distribution of $\theta$ is given by

$$
p\left(\theta \mid X_{T}, \mathscr{M}_{i}\right) \propto L\left(X_{T} \mid \theta, \mathscr{M}_{i}\right) p\left(\theta \mid \mathscr{M}_{i}\right) .
$$

This posterior distribution is evaluated numerically using the Metropolis-Hastings algorithm with 300,000 draws. The first 25\% draws are discarded to eliminate dependence on the initializing values chosen for $\theta$.

For the sake of comparing different model versions, we resort to the following two standard criteria. First, from $p\left(\theta \mid X_{T}, \mathscr{M}_{i}\right)$, one can compute the marginal likelihood of specification $\mathscr{M}_{i}$, which is defined by

$$
L\left(X_{T} \mid \mathscr{M}_{i}\right)=\int L\left(X_{T} \mid \theta, \mathscr{M}_{i}\right) p\left(\theta \mid \mathscr{M}_{i}\right) \mathrm{d} \theta
$$

A benefit of resorting to this measure of fit is that it accounts for the effects of the prior distribution (An and Schorfheide, 2007). Second, given a prior probability $p_{i}$ on a given model specification $\mathscr{M}_{i}$, the posterior odds ratio is defined as

$$
\mathcal{P}_{i, T}=\frac{p_{i} L\left(X_{T} \mid \mathscr{M}_{i}\right)}{\sum_{j=0}^{M-1} p_{j} L\left(X_{T} \mid \mathscr{M}_{j}\right)} \quad \text { with } \quad \sum_{j=0}^{M-1} p_{j}=1,
$$

where $M$ is the number of model specifications considered. We defer until next subsection the discussion of the particular model versions which we consider in our empirical analysis.

\subsection{Prior Distribution}

We partition the model parameters into two groups. The first one collects the parameters which we calibrate prior to estimation. These include parameters that can be given a value based on first-order moments, as well as parameters that cannot be separately identified. Let $\theta^{c} \equiv\left(\beta, s_{x}, \gamma, \theta_{p}, \theta_{w}, \epsilon_{\mu}\right)^{\prime}$ denote the vector of calibrated parameters. The first three parameters can be calibrated to mimic "great ratios" and the last three raise specific problems. We thus impose "dogmatic" priors on $\theta^{c}$.

Following Smets and Wouters (2003), we set $\beta=0.99$. The growth rate of technical progress is set to the mean growth rate of output, $\gamma=1.0045$. Finally, we impose $s_{x}=0.5$, which matches the euro area figure reported by Jellema et al. (2006). We chose to calibrate $\theta_{p}, \theta_{w}$ and $\epsilon_{\mu}$ because these 
parameters cannot be separately identified as long as we want to estimate the probabilities of price and wage fixity, namely $\alpha_{p}$ and $\alpha_{w}$. The reason why is simple. Note that $\alpha_{w}$ and $\theta_{w}$ appear only in the definition of $\kappa_{w}$. Fundamentally, the data allow us only to estimate the partial elasticity of wage inflation with respect to the labor disutility wedge, and many combinations of $\alpha_{w}$ and $\theta_{w}$ are compatible with a given estimate of this partial elasticity, as explained by Rotemberg and Woodford (1997) and Amato and Laubach (2003). Though less evident a priori when it comes to $\alpha_{p}, \epsilon_{\mu}$, and $\theta_{p}$, we encountered similar difficulties when trying to estimate these parameters. Here, we choose to estimate $\alpha_{p}$ and $\alpha_{w}$, which requires that the other parameters related to stickiness be calibrated prior to estimation. As in Rabanal and Rubio-Ramírez (2007), we set $\theta_{p}=6$, so that the long-run markup charged by intermediate goods producers amounts to $20 \%$, and $\theta_{w}=11$, so that the markup charged on wages amounts to $10 \%$. Finally, we set $\epsilon_{\mu}=1$. As argued by Chari et al. (2000), it is important that this value be set to generate a reasonable curvature of the demand function faced by a monopolist. With the chosen value, we obtain that a $2 \%$ increase in relative prices results in a $14.8 \%$ decline in demand. This value is close to what obtains with a constant elasticity of demand $\left(\epsilon_{\mu}=0\right)$, in which case a $2 \%$ increase in relative prices results in a $11.2 \%$ decline in demand.

In the benchmark model version, labelled $\mathscr{M}_{0}$, the remaining 21 parameters are estimated. Thus, in our empirical analysis, we set

$$
\theta=\left(b, \omega, \gamma_{p}, \gamma_{w}, \alpha_{p}, \alpha_{w}, \rho, a_{p}, a_{y}, \rho_{z}, \rho_{p}, \rho_{w}, \rho_{g}, \rho_{R}, \rho_{\pi}, \sigma_{z}, \sigma_{p}, \sigma_{w}, \sigma_{g}, \sigma_{R}, \sigma_{\pi}\right)^{\prime}
$$

We now discuss our choice of priors. When it comes to the utility parameters, these are based on the prior belief that it takes a high degree of habit formation and a low elasticity of labor supply to match the data (see, e.g., Smets and Wouters, 2003, Rabanal and Rubio-Ramírez, 2007). At the same time, previous estimation results in the literature suggest that $\omega$ is difficult to estimate precisely. Indeed, the aggregate data typically used in the literature often have nothing to say about this parameter. Thus, we must combine our prior belief that $\omega$ is high with the fact that relatively little is known on this parameter at the aggregate level. Accordingly, we adopt a normal distribution for $\omega$, with a prior mean set to 2 and a standard error set to 0.5 . While still informative, this prior distribution is dispersed enough to allow for a wide range of possible and realistic values to be considered. For the habit parameter, we adopt a Beta prior, ensuring that this parameter belongs to $[0,1]$. The prior mean is set to 0.7 , with a standard error of 0.05 . This strict prior, when compared to that adopted for $\rho_{g}$ (see below), is important because it reflects our belief that the habit channel 
is a more important propagation mechanism than the autocorrelation coefficient of demand shocks.

When it comes to the parameters governing nominal rigidities $\left(\alpha_{p}, \alpha_{w}, \gamma_{p}, \gamma_{w}\right)$, we adopt Beta distributions. For the Calvo probabilities, our prior belief, based on previous empirical work, suggests high values. In particular, the thorough study conducted by the ECB's Inflation Persistence Network, as summarized by Dhyne et al. (2006), indicates that the average price duration is close to one year in the euro area. Preliminary results for the ECB's Wage Dynamics Network provide similar results for average wage duration. We thus set both prior means to 0.75 with a low standard error of 0.05. We adopt less strict priors for the indexation parameters, with prior means set to 0.5 and standard errors set to 0.15 . These are consistent with priors adopted by Smets and Wouters (2003).

When it comes to the monetary policy parameters, namely $a_{p}, a_{y}$ and $\rho$, we adopt analog priors as those used by Smets and Wouters (2003). More precisely, $a_{p}$ and $a_{y}$ are assumed to be normally distributed, with means 1.7 and 0.125 , respectively and associated standard errors of 0.15 and 0.05 , respectively. For the degree of nominal interest rate smoothing, $\rho$, we adopt a Beta distribution, with mean set to 0.75 and standard error set to 0.1 .

All the standard errors of shocks are assumed to be distributed according to inverted Gamma distributions. The latter ensures that these parameters have a positive support. The chosen means for these prior distributions are based on preliminary investigations and previous empirical results. For example, we assume a lower standard error for the two monetary policy shocks than for the other shocks. To ensure as wide a support as reasonable, we assume a common standard error for these distributions, set to 0.1. The autoregressive parameters are all assumed to follow Beta distributions. Except for technology shocks, all these distributions are centered on 0.75. For technology shocks, a much lower mean of 0.25 is adopted. This reflects our prior belief that TFP growth is only mildly serially correlated, if ever. We assume a common standard error of 0.15 , slightly larger than that assumed by Smets and Wouters (2003). Once again, we allow for a much lower standard error for the prior distribution of $\rho_{z}$, reflecting our prior belief that the technology shock is not highly serially correlated.

We also consider two other model versions. In $\mathscr{M}_{1}$, we dogmatically set $\rho_{\pi}=0$. Hence, in this model version, we assume that the inflation target follows a simple random walk, resembling the stochastic process postulated by Ireland and Smets and Wouters. This specification allows us to assess the 
consequence of shutting down a possibly important channel of monetary policy inertia. Notice that this assumption affects only the transmission mechanism of inflation target shocks. In this exercise, of course, all the remaining parameters in $\theta$ are re-estimated. In $\mathscr{M}_{2}$, we dogmatically set $\rho=0$. In this case, the traditional representation of monetary policy inertia, namely nominal interest rate smoothing, is ignored. This assumption does not only affect the propagation dynamics of inflation target shocks, it also impacts on the transmission of all the shocks included in the analysis. Once again, all the remaining parameters in $\theta$ are re-estimated. In these alternative model versions, we adopt the same priors as in the benchmark specification. The choice of parameters priors for each model version is summarized in the left panel of table 1.

\subsection{Estimation Results}

For the benchmark specification, the estimation results, together with the priors, are graphically summarized in figure 2. In each case, the dark grey line is the posterior distribution while the light grey line corresponds to the prior distribution. Also, the vertical dashed line denotes the posterior mode. The results are also reported in the right panels of table 1. For each model version, the table shows the posterior mean and the $95 \%$ HPD interval. ${ }^{5}$

The mean habit parameter is $b=0.83$. This value is slightly higher than that found by Smets and Wouters (2003). This should not come as a surprise given that we estimate a smaller model in which no formal distinction is established between output and consumption. ${ }^{6}$ Concerning the utility parameter $\omega$, we obtain a mean value of 2.11. Notice that this figure is hardly different from the prior mean. This is particularly evident upon inspecting figure 2, which reveals that the prior and posterior distributions are almost identical. This result is familiar in the literature. In particular,

\footnotetext{
${ }^{5}$ Notice that the likelihood might be multipeaked when we allow for both partial adjustment and for serially correlated shocks (Blinder, 1986, McManus et al., 1994, Sargent, 1978). This can happen for the Euler equation on consumption (habit channel versus preference shocks), for the Phillips curves on price and wages (indexation versus cost push shocks), and for the Taylor rule (interest rate smoothing versus monetary policy shocks). While in all these cases we used approximately the same priors for partial adjustment parameters and for the degree of serial correlation of shocks, the posterior distribution always favors the partial adjustment parameter, irrespective of the particular random initial condition used in the numerical algorithm. This suggests that the multipeaked likelihood curse might not be a problem in our empirical analysis.

${ }^{6}$ Woodford (2003) discusses circumstances in which habit persistence in a small model like ours is compatible with an interpretation of $y_{t}$ as private expenditures instead of consumption expenditures.
} 
Smets and Wouters (2003) obtain a similar syndrom of a lack of identification.

When it comes to the indexation parameters, we obtain the following results. The wage indexation parameter is $\gamma_{w}=0.3951$, higher than $\gamma_{p}=0.1656$. Interestingly, the euro area data do not require too high a degree of price indexation. This result is now standard in the literature (Smets and Wouters, 2003, 2005, Rabanal and Rubio-Ramìrez, 2007).

The probability of no price change is $\alpha_{p}=0.82$, which is fairly high, especially when one acknowledges that our model incorporates many features devised to lower the estimated value of this parameter (material goods, variable elasticity of demand). This is suggestive of a flat Phillips curve. Notice however that the 95\% HPD interval is consistent with the value obtained by the ECB's Inflation Persistence Network, as reported in Dhyne et al. (2006). The probability of no wage change is $\alpha_{w}=0.7756$. This value is consistent with preliminary results reported by the ECB's Wage Dynamics Network.

When it comes to the monetary policy rule parameters $\left(\rho, a_{p}\right.$ and $\left.a_{y}\right)$, we obtain almost the same results as Smets and Wouters (2003). The degree of nominal interest rate smoothing is found to be important with $\rho=0.8623$. Monetary policy has been pretty aggressive in response to deviations of the inflation gap, since $a_{p}=1.5229$. This value is sufficiently large that the Taylor principle is successfully enforced. Finally, $a_{y}=0.1797$, suggesting that monetary policy granted a moderate amount of attention the stabilizing real activity.

The parameters governing the shock dynamics deserve several comments. First, we obtain relatively small degrees of serial correlation for all the shocks. This suggests that the model in itself contains sufficient endogenous propagation channels that it does not have to rely on exogenous sources of persistence. The highest serial correlation parameters are $\rho_{w}=0.7421$ and $\rho_{\pi}=0.7205$. The mean value of $\rho_{\pi}$ implies a half-life for inflation target shocks of slightly more than three quarters and a half. This suggests that the stand-in central bank has adjusted slowly its inflation target. The standard errors of shocks are also very similar to what Smets and Wouters (2003) obtained.

It is interesting to compare the estimation results obtained with our benchmark specification to those obtained under the alternative two model specifications. First, notice that the marginal likelihoods shows that the benchmark model version $\mathscr{M}_{0}$ is favored by the data. This suggests that a scenario with both inflation target inertia and nominal interest rate inertia is preferred to each of the two alternative where one form of inertia has been shut down. Inspecting the posterior odds ratios, one 
can get a complementary way of seeing this. Starting from a prior distribution on model versions with $p_{j}=1 / 3$ for $j=0,1,2$, one arrives at the following $\mathcal{P}_{0}=0.77, \mathcal{P}_{1}=0.23$, and $\mathcal{P}_{2}=0.00$. Therefore, the prior distribution on model versions is severly shifted towards version 0, which gains more than three quarters of the whole probability mass.

The key differences between parameter estimates in the various model versions are as follows. First, upon comparing models $\mathscr{M}_{0}$ and $\mathscr{M}_{1}$, we see that the structural parameters are almost identical, except for the degree of serial correlation of shocks which is always higher in model version $\mathscr{M}_{1}$. As we argue later, an important propagation channel has been eliminated in $\mathscr{M}_{1}$, so that we left no other choice to this specification but to increase the remaining sources of persistence. Notice also that, mechanically, $\sigma_{\pi}$ is twice as large in $\mathscr{M}_{1}$ as in $\mathscr{M}_{0}$. Second, upon comparing models $\mathscr{M}_{0}$ and $\mathscr{M}_{2}$, the first striking fact is that the habit and wage indexation parameters are now extremely high in version $\mathscr{M}_{2}$ (0.9106 and 0.8206 , respectively), compared with $\mathscr{M}_{0}$. The second striking fact is that imposing $\rho=0$ has dramatic effects on the shape of the policy rule. In particular, the inflation and output gaps feedbacks are much reduced. In the meantime, shutting the interest rate smoothing channel down translated into a much higher degree of serial correlation of monetary policy shocks, since $\rho_{R}=0.9535$. Finally, $\sigma_{R}$ is three times as large in $\mathscr{M}_{2}$ as in $\mathscr{M}_{0}$.

\subsection{Implications of Inflation Target Shocks}

In this subsection, we use the estimated model to perform several standard exercises aimed at analyzing the dynamic properties of our framework. Here, we essentially focus our analysis on the dynamic effects of an inflation target shock. We first inspect the impulse response functions (IRFs) triggered by this particular shock. These are compared to the IRFs resulting from a standard monetary policy shock. Second, we compute the contribution of inflation target shocks to aggregate fluctuations.

Before proceeding, it is interesting to compare actual inflation dynamics with the time profile of the unobserved inflation target that our estimation procedure allows us to reveal. As is customary, the latter is obtained using the full sample information contained in the smoothed inflation target shocks. Figure 3 reports in plain line actual demeaned inflation; the dotted line corresponds to the smoothed estimate of the inflation target. As before, the grey area highlights the disinflation period experienced by the euro area in the eighties. As the figure makes clear, the inflation target tracks 
all the medium to low frequency movements of inflation. Interestingly, however, it does not fully capture the inflation peaks experienced over the seventies. Arguably, adverse supply shocks are to be held responsible for these peaks. In contrast, the inflation target mimicks well the sharp decline in inflation experienced in the early eighties.

Figure 4 reports the dynamic responses of aggregate variables after a one standard error percent, negative inflation target shock. For each variable, the figure includes the HPD intervals at different levels (95\%, light gray, and $68 \%$, dark gray). Also, the thick line is the mean impulse response function (IRF) while the dotted line is the median response. ${ }^{7}$

Inflation displays a regular and slow decline to its new long-run value. The average long-run response is approximately equal to $-0.25 \%$, thus leading to a decline by one percentage point in annualized inflation. Notice that it takes more than 20 quarters to approximately reach the new steady state value. At the same time, the nominal interest rate is almost unresponsive on impact and then gradually declines. This implies a significant rise in the real interest rate in the immediate aftermath of the inflation target shock. In addition, the overall dynamics of the nominal interest rate appear significantly slower than for inflation. As a consequence, the rise in the real (ex-ante) interest rate turns out to be very persistent.

As is expected from the dynamics of the real interest rate, output reacts negatively on impact to a decline in the inflation target. To understand this, recall that, after eliminating inessential terms, equations (6) and (7) can be combined together to yield

$$
y_{t}^{s}=b y_{t-1}^{s}-\frac{(1-\beta b)(1-b)}{\beta b} \mathrm{E}_{t}\left\{\sum_{j=0}^{\infty} \hat{r}_{t+j}\right\} \text {, }
$$

where $\hat{r}_{t} \equiv \hat{R}_{t}-\mathrm{E}_{t}\left\{\hat{\pi}_{t+1}\right\}$ is the real ex-ante interest rate. As in Boivin and Giannoni (2006), we interpret the term in curly brackets as the long term real interest rate, the latter being simply the infinite cumulated sum of ex-ante real short term rates. Thus, output negatively responds to this long term real rate. As a consequence, if monetary policy induces persistent increases in the real interest rate, the negative output response will be more pronounced and more persistent. This is precisely what happens here. Moreover, the inflation target shock induces a delayed, inverted-humpshaped output response. Output reaches its lowest response after about height quarters. Finally, after twenty quarters, output reverts back to its initial response, suggesting a very long-lasting effect

\footnotetext{
${ }^{7}$ All these IRFs are computed by drawing 5,000 values of $\theta$ in the posterior distribution.
} 
of the inflation target shock. To confirm this, it is instructive to inspect the sacrifice ratio implied by this shock, which we compute as the cumulated response of output divided by the annualized change in inflation. The traditional interpretation of this statistic is that it represents the total output loss consecutive to a purposeful disinflation. After twenty quarters, the sacrifice ratio is slightly higher than 7.5 with a $95 \%$ HPD interval delimited by 5 and 10. This is thus illustrative of the large effects of a negative inflation target shock on output.

In the short-run, wage inflation displays a similar pattern as that of inflation but since our estimates suggest greater price stickiness than nominal wage stickiness, the real wage decreases in a protracted fashion. The lowest response is reached after about 13 quarters. The real wage dynamics turn out to be even more persistent than that of output. This result is interesting because it suggests that the disinflation period in the euro area was not associated with excessively high real wages. Instead, our estimated model highlights the importance of real interest rate dynamics. This calls for a thorough assessment of the role of monetary policy in the depressed growth period experienced by the euro area in the eighties.

For the sake of comparison, it is interesting to contrast these IRFs with those arising from a (one standard error percent) monetary policy shock $\eta_{R, t}$. These IRFs are reported on figure 5 . Before proceeding, notice that, once corrected for their respective degrees of serial correlation, both $\eta_{R, t}$ and $\Delta \pi_{t}^{\star}$ have the same overall amount of variance. This allows us to conduct this comparison exercise, with appropriately scaled dynamic responses.

Several striking conclusions emerge from this comparison. First, the overall inverted-hump shape of the real wage and output responses is very similar to what obtained in the case of an inflation target shock. Notice though that these dynamics are less persistent: after a temporary increase in the nominal interest rate, the lowest response of output is reached after about six quarters and the lowest response of the real wage obtains roughly ten quarters after the shock. Second, the amplitude of these response is smaller than what obtained in figure 4. Third, the impact response of inflation is much smaller than after an inflation target shock. In addition, the overall inflation response seems pretty muted, reflecting the high degree of nominal rigidity found in the estimation stage. Nevertheless, inflation displays a substantial degree of persistence and takes a long time to revert back to its initial position. The nominal interest rate increases in a hump-shaped manner and takes time to revert back to its initial position. This pattern is reminiscent of estimates of the dynamic response of $R_{t}$ to 
monetary policy shocks obtained in structural vector autoregressive models estimated on European data (see, e.g., Peersman, 2004). Finally, the real interest rate persistently increases too, but to a much smaller extent than in response to an inflation target shock. This is the key difference between those two monetary policy shocks: the inflation target shock has very long lasting effects on the real interest rate and thus on output, while the standard monetary policy shock has milder effects on those same variables.

To conclude this section, we assess the contribution of the inflation target shock to aggregate fluctuations. Table 2 reports the forecast error variance decomposition at different horizons. This exercise is conducted in all three estimated model versions discussed above.

In the benchmark specification, $\mathscr{M}_{0}$, the fluctuations of nominal variables (inflation, wage inflation and the nominal interest rate) are essentially explained by the inflation target shock, even in the short-run, except maybe for the nominal interest rate. For example, it accounts for $54 \%$ of inflation, $30 \%$ of wage inflation and $9 \%$ of the nominal interest rate after four quarters. At longer horizons, this shock explains by construction all the fluctuations in the nominal variables. Though the DSGE model implies long-run neutrality of monetary policy shocks, the inflation target shock has sizeable effects on real variables. For example, it account approximatively for $38 \%$ and $50 \%$ of the variance of output after four and twelve quarters, respectively. Additionally, it represents $38 \%$ of the variance of the real interest rate after twelve quarters. This contribution is smaller for the real wage. At longer horizons (ten years), this shock represents $30 \%, 42 \%$ and $15 \%$ of output, real interest rate and real wage fluctuations, respectively.

These findings contrast with what obtains in model $\mathscr{M}_{1}\left(\rho_{\pi}=0\right)$. Indeed, in this case, the inflation target shock explains only a trivial portion of output dynamics. This is due to the fact that at medium to long horizons, this shock has a smaller contribution to fluctuations in the real interest rate when compared to the benchmark case. This result emphasizes the key role of gradual inflation target shocks. Notice that our results in $\mathscr{M}_{1}$ are very similar to what Ireland (2007) obtains on US data. Recall that in his specification, the inflation target follows a simple random walk. While this might be a defendible hypothesis for the US case, our empirical results suggest that it is less tenable for euro area data. Finally, in model $\mathscr{M}_{2}(\rho=0)$, we obtain an even smaller contribution of inflation target shocks to all real variables. This indicates that the shape of monetary policy itself has played a significant role in the propagation of inflation target shocks. 


\section{Counterfactual Analysis on Monetary Policy}

The preceeding section has highlighted the crucial role of gradual monetary policy in shaping the euro area business cycle. Armed with these empirical results, we now turn our attention to a counterfactual analysis of gradual monetary policy. This exercise is legitimate in the sense that our structural model is in principle immune to the Lucas critique and thus serves as a natural tool to investigate various monetary policy experiments. All these quantitative experiments are conducted using our benchmark model specification $\mathscr{M}_{0}$.

\subsection{What Happens When There Are No Inflation Target Shocks?}

In order to assess the role played by the inflation target shock, we compute counterfactual sample pathes for inflation, output, real wage, the nominal interest rate, and the real (ex-ante) interest rate implied by the model, as in Ireland (2007). These samples are obtained using the following straightforward procedure. We first assume that no inflation target shocks whatsoever occured and feed the benchmark model with the remaining five smoothed shocks. The resulting sample pathes are reported in figure 6 . The solid line corresponds to the benchmark case. Because we simulate the model with smoothed shocks, these simulated data correspond to actual data. The dotted line is the counterfactual path, wherein the inflation target shock is set to zero in each and every period. Finally, the figure also reports a shaded area corresponding to the disinflation period experienced by euro area countries.

In this counterfactual experiment, the long-run and non-stationary component of inflation is eliminated. As a consequence, the large downswing in inflation that occured in the 1980's is absent from the simulated path. Notice that, in spite of this, inflation continues to exhibit a substantial amount of low frequency movements, reflecting the high degree of nominal rigidities found in the estimated model. Another interesting feature is the time profile of the stochastic growth component of output (i.e. that portion of output dynamics not explained by the deterministic part of exogenous productivity). During the seventies, shuting the inflation target shock down does not alter much the dynamics of output. On the contrary, during the eighties (shaded area), the euro zone would have experienced strikingly more sustained growth than it actually did if it had not been subject to negative inflation target shocks. The traditional explanations for the protracted period of depressed 
growth in the euro area consecutive to disinflation policies are (i) too high a real wage (due to nominal wage rigidities) and (ii) too high a real interest rate. Given that our model attributes a large part of the decline in output to negative inflation target shocks, it is interesting to study what would have been the dynamics of the real wage and the real interest rate absent these shocks. As was to be expected from the previous section, we find that the real wage is hardly affected by the omission of the inflation target shock. Real wages would have been slightly higher in the mid eighties had it not been for the disinflation shocks. Our main finding in this exercise is that the dynamics of the real (ex-ante) interest rate is much more affected by omitting the inflation target shocks. Indeed, the real interest rate would have fallen in the early eighties and remained below its actual path during the eighties if inflation target shocks had not hit the economy.

\subsection{Consequences of Alternative Monetary Policies}

The previous exercise suggests a non trivial role of monetary policy in our sample. To investigate further this issue, we use our estimated version of the DSGE model to perform counterfactual analyses focused only on the shape of monetary policy. These exercises are meant to shed additional light on the main mechanisms at work after a permanent change in the inflation target. In each experiment, the estimated model is used as our benchmark. We modify the two key parameters $\rho_{\pi}$ and $\rho$ capturing the observed persistence in monetary policy. These counterfactual experiments about monetary policy are investigated by inspecting how the dynamic responses of inflation, output, the real wage, the nominal interest rate, and the real (ex-ante) interest rate differ from the benchmark responses. All the results are reported in figures 7 .

Immediate Diffusion of Inflation Target Shocks. We first investigate whether the persistence in the inflation target has played a sizeable role in the depressive effect of disinflation policies. The idea is to assess whether a faster adjustment of the inflation target to its new value could have altered the dynamic responses of aggregate variables in the Euro zone. This quantitative analysis echoes previous debates about the optimal speed of disinflation (see Taylor, 1983, and Sargent, 1983). It is worth noting that empirical studies suggest that a higher disinflation speed often results in a lower output loss (see Ball, 1994, and Boschen and Weise, 2001). To investigate this, we set $\rho_{\pi}=0$ in our first experiment. 
As shown in figure 7 , inflation drops very quickly to its new long-run value (in approximately 3 periods). At the same time, the response of the real wage and output are almost twice as small as what obtained in the benchmark case. As before, the decline in output follows from the response of the real interest rate. Recall that in this first experiment, the remaining monetary policy parameters are left unchanged. This means that the nominal interest rate reacts very little in the short run to the disinflation shock, given the estimated degree of interest rate smoothing. This creates a large impact increase in the real interest rate. At the same time, the real interest rate returns to its steady state value at a faster pace than in the benchmark scenario, thus leading to a smaller decline in output.

No Nominal Interest Rate Inertia. A second, somewhat related, experiment considers the adjustment speed of the nominal interest rate. Monetary policy inertia is somewhat akin to the gradual diffusion of inflation target shocks in terms of adjustment speed of nominal variables. However, it acts differently in that a higher nominal interest rate inertia can disconnect the nominal rate from inflation in the short-run . For example, if the nominal interest rate is almost unresponsive in the short-run whereas the inflation target reaches its new (lower) long-run value, one should expect a persistent increase in the real interest rate translating into a sizeable output loss. Thus, in this second experiment, we set $\rho=0$.

We see from figure 7 , that this new form of monetary policy has strong implications on the dynamic responses of output and the real interest rate. At the same time, the response of inflation is almost unaffected in comparison to the benchmark case and the real wage is almost unresponsive. These results suggest that the speed of adjustment to the targeted nominal interest rate governs a large part of the model's dynamics. Here, since monetary policy displays no inertia, the nominal interest rate follows closely the inflation rate. As a consequence, the real interest rate is almost unresponsive and thus the output loss consecutive to a disinflation shock is very small. This finding suggests that the form of monetary policy, namely monetary policy inertia, has played an important role in the large and persistent increase of the real interest rate and the sizeable output loss that have followed from disinflation policies in the eighties.

No Diffusion - No Inertia. The last experiment mixes the previous two, i.e. an immediate adjustment of the inflation target combined with no monetary policy inertia $\left(\rho=\rho_{\pi}=0\right)$. In 
this situation, inflation adjusts very quickly to its new long-run value and the disinflation shock has almost no effect on output. Once again, this obtains because the real interest rate is almost unresponsive to this shock.

\section{Concluding Remarks}

In this paper, we have attempted to quantify the importance of inflation target shocks in the euro zone business cycle. To do so, we formulated a DSGE model with various real and nominal frictions. Our main results are that these shocks are important insofar as changes in the inflation target are gradual. This hypothesis is strongly supported by the data, based on marginal likelihood rankings. In addition, our framework enables us to disentangle the respective roles of excessive and persistent real wages and real interest rates in explaining the protracted period of depressed economic activity in the euro area over the eighties. Our findings suggest that real wages played a minor role while real interest rates seem to be the essential part of the story. Running several counterfactual experiments, we find that monetary policy itself, due to gradualism and inertia, is responsible for the observed dynamics of the real interest rate. 


\section{References}

Adolfson, M., Laséen, S., Lindé, J., Villani, M., 2005. The role of sticky prices in an open economy DSGE model: a Bayesian investigation. Journal of the European Economic Association, 3, 444-457. Adolfson, M., Laséen, S., Lindé, J., Villani, M., 2007. Bayesian estimation of an open economy DSGE model with incomplete pass-through. Journal of International Economics, 72, 481-511.

Amato, J.D., Laubach, T., 2003. Estimation and control of an optimization-based model with sticky prices and wages. Journal of Economic Dynamics and Control, 27, 1181-1215.

An, S., Schorfheide, F., 2007. Bayesian analysis of DSGE models. Econometric Reviews, 26, 13-172. Ball, L., 1994. What determines the sacrifice ratio? In Mankiw, G. (Ed.) Monetary policy, University of Chicago Press, 155-88.

Blanchard, O.J., 2003. Monetary policy and unemployement. Remarks at the Conference Monetary Policy and the Labor Market. A conference in honor of James Tobin.

Blinder, A.S., 1986. More on the speed of adjustment in inventory models. Journal of Money, Credit, and Banking, 18, 355-365.

Boivin, J., Giannoni, M., 2006. Has monetary policy become more effective. Review of Economics and Statistics, 88, 445-462.

Boschen, J., Weise, C., 2001. Is delayed disinflation more costly? Southern Economic Journal, 67, 701-712.

Calvo, G., 1983. Staggered prices in a utility-maximizing framework. Journal of Monetary Economics, 12, 383-398.

Chari, V.V., Kehoe, P.J., McGrattan, E.R., 2000. Sticky price models of the business cycle: Can the contract multiplier solve the persistence problem? Econometrica, 68, 1151-1179.

Coenen, G., McAdam, P., Straub, R., 2008. Tax reforms and labour market performance in the

euro area: A simulation-based analysis using the New Area-Wide Model. Forthcoming, Journal of Economic Dynamics and Control.

Cogley, T., Sbordone, A.M., 2007. Trend Inflation, Indexation, and Inflation Persistence in the New Keynesian Phillips Curve. Forthcoming, American Economic Review. 
Cochrane, J., 2007. Identification with Taylor Rules: A Critical Review. Mimeo.

de Walque, G., Smets, F., and Wouters, R., 2006. Firm-specific production factors in a DSGE Model with Taylor price setting. International Journal of Central Banking, 2, 107-154.

Dhyne, E., Álvarez, L.J., Le Bihan, H., Veronese, G., Dias, D., Hoffman, J., Jonker, N., Lünnemann, P., Rumler, F., Vilmunen, J., 2006. Price changes in the euro area and in the United States: Some facts from individual consumer price data. Journal of Economic Perspectives, 20, 171-192.

Edge, R.M., Kiley, N.T., Laforte, J.P., 2007. Natural rate measures in an estimated DSGE model of the U.S. economy. Finance and Economics Discussion Series, 2007-08, Federal Reserve Board.

Erceg, C.J., Henderson, D.W., Levin, A.T., 2000. Optimal monetary policy with staggered wage and price contracts. Journal of Monetary Economics, 46, 281-313.

Erceg, C.J. and Levin, A.T., 2003. Imperfect credibility and inflation persistence. Journal of Monetary Economics, 50, 915-944

Fagan, G., Henry, J., and Mestre, R., 2005. An Area-Wide Model (AWM) for the euro-area. Economic Modelling, 22, 39-59.

Ireland, P., 2007. Changes in the Federal Reserve's inflation target: Causes and consequences. Journal of Money, Credit and Banking, 39, 1851-1882.

Jellema, T., Keuning, S., McAdam, P., and Mink, R., 2006. Developing a euro area accounting matrix: issues and applications. In: de Janvry, A., Kanbur, R. (Eds.), Poverty, Inequality and Development, Kluwer Academic Press.

Kimball, M.S., 1995. The quantitative analytics of the basic neomonetarist model. Journal of Money, Credit, and Banking, 27, 1241-1277.

Laforte, J.P., 2007. Pricing models: a Bayesian DSGE approach for the US economy. Journal of Money, Credit, and Banking, 39, 127-154.

McManus, D.A., Nankervis, J.C., Savin N.E., 1994. Multiple optima and asymptotic approximations in the partial adjustment model. Journal of Econometrics, 62, 91-128.

Melecky, M., Rodríguez-Palenzuela, D., Söderström, U., 2008. Inflation target transparency and the macroeconomy. Mimeo, IGIER-Bocconi. 
Peersman, G., 2004. The transmission of monetary policy in the euro area: Are the effects different across countries? Oxford Bulletin of Economics and Statistics, 66, 285-308.

Rabanal, P., Rubio-Ramírez, J.F., 2007. Comparing New Keynesian Models in the Euro Area: A Bayesian Approach. Forthcoming in the Spanish Economic Review

Rotemberg, J.J., Woodford, M., 1997. An optimization-based econometric framework for the evaluation of monetary policy. In: Bernanke, B.S., Rotemberg, J.J. (Eds.), NBER Macroeconomics Annual. MIT Press, Cambridge, 297-346.

Sargent, T.J., 1978. Estimation of dynamic labor demand schedules under rational expectations. Journal of Political Economy, 86, 1009-1044.

Sargent, T.J., 1983. Stopping moderate inflations: The methods of Poincare and Thatcher. In Dornbusch, R., Simonsen, M. (Eds.) In Inflation, Debt, and Indexation, Cambridge MA: MIT Press, pp. 54-96.

Smets, F. and Wouters, R., 2003. An estimated dynamic stochastic general equilibrium model of the euro-area. Journal of the European Economic Association, 1, 1123-1175

Smets, F. and Wouters, R., 2005. Comparing shocks and frictions in US and euro-area business cycles: a Bayesian DSGE approach. Journal of Applied Econometrics, 20, 161-183.

Taylor, J.B., 1983. Union wage settlements during a disinflation, American Economic Review, 73, 980-993.

Woodford, M., 2003. Interest and Prices. Princeton University Press. 
Table 1. Structural parameter estimates, 1970(1)-2004(4)

\begin{tabular}{|c|c|c|c|c|c|c|c|c|c|c|c|c|}
\hline & \multicolumn{3}{|c|}{ Prior distribution } & \multicolumn{9}{|c|}{ Posterior distribution } \\
\hline & \multirow[b]{2}{*}{ Type } & \multirow[b]{2}{*}{ Mean } & \multirow[b]{2}{*}{ S.E. } & \multicolumn{3}{|c|}{$\mathscr{M}_{0}$} & \multicolumn{3}{|c|}{$\mathscr{M}_{1}$} & \multicolumn{3}{|c|}{$\mathscr{M}_{2}$} \\
\hline & & & & $5 \%$ & Mean & $95 \%$ & $5 \%$ & Mean & $95 \%$ & $5 \%$ & Mean & $95 \%$ \\
\hline$b$ & beta & 0.7000 & 0.0500 & 0.7956 & 0.8384 & 0.8804 & 0.8052 & 0.8468 & 0.8935 & 0.9012 & 0.9106 & 0.9281 \\
\hline$\omega$ & normal & 2.0000 & 0.5000 & 1.2930 & 2.1147 & 2.9127 & 1.3609 & 2.1288 & 2.9363 & 2.2693 & 2.5598 & 3.2185 \\
\hline$\gamma_{p}$ & beta & 0.5000 & 0.1500 & 0.0610 & 0.1656 & 0.2732 & 0.0756 & 0.1928 & 0.3182 & 0.1215 & 0.1928 & 0.2758 \\
\hline$\gamma_{w}$ & beta & 0.5000 & 0.1500 & 0.1871 & 0.3951 & 0.6003 & 0.2126 & 0.4198 & 0.6233 & 0.6886 & 0.8206 & 0.9303 \\
\hline$\alpha_{p}$ & beta & 0.7500 & 0.0500 & 0.7594 & 0.8225 & 0.8864 & 0.7382 & 0.8050 & 0.8754 & 0.6810 & 0.7123 & 0.7490 \\
\hline$\alpha_{w}$ & beta & 0.7500 & 0.0500 & 0.7006 & 0.7756 & 0.8500 & 0.6858 & 0.7681 & 0.8433 & 0.6961 & 0.7341 & 0.7900 \\
\hline$\rho$ & beta & 0.7500 & 0.1000 & 0.8317 & 0.8623 & 0.8951 & 0.8248 & 0.8584 & 0.8898 & - & - & - \\
\hline$a_{p}$ & normal & 1.7000 & 0.1500 & 1.2680 & 1.5229 & 1.7760 & 1.2871 & 1.5317 & 1.7804 & 1.0000 & 1.2231 & 1.5186 \\
\hline$a_{y}$ & normal & 0.1250 & 0.0500 & 0.1036 & 0.1797 & 0.2590 & 0.0963 & 0.1809 & 0.2572 & 0.0154 & 0.0593 & 0.0978 \\
\hline$\rho_{z}$ & beta & 0.2500 & 0.0500 & 0.1638 & 0.2498 & 0.3263 & 0.1649 & 0.2506 & 0.3281 & 0.1714 & 0.2500 & 0.3347 \\
\hline$\rho_{p}$ & beta & 0.7500 & 0.1500 & 0.0908 & 0.2300 & 0.3595 & 0.1144 & 0.2709 & 0.4265 & 0.1124 & 0.2131 & 0.3410 \\
\hline$\rho_{w}$ & beta & 0.7500 & 0.1500 & 0.6457 & 0.7421 & 0.8533 & 0.6573 & 0.7588 & 0.8575 & 0.6060 & 0.7135 & 0.8072 \\
\hline$\rho_{g}$ & beta & 0.7500 & 0.1500 & 0.2284 & 0.4193 & 0.6177 & 0.3294 & 0.5078 & 0.6696 & 0.1786 & 0.2989 & 0.4060 \\
\hline$\rho_{R}$ & beta & 0.7500 & 0.1500 & 0.2830 & 0.3868 & 0.4955 & 0.2901 & 0.4023 & 0.5077 & 0.9397 & 0.9535 & 0.9523 \\
\hline$\rho_{\pi}$ & beta & 0.7500 & 0.1500 & 0.5613 & 0.7205 & 0.8821 & - & - & - & 0.5054 & 0.6790 & 0.8399 \\
\hline$\sigma_{z}$ & inv. gamma & 0.0100 & 0.1000 & 0.0041 & 0.0049 & 0.0058 & 0.0041 & 0.0050 & 0.0059 & 0.0050 & 0.0056 & 0.0062 \\
\hline$\sigma_{p}$ & inv. gamma & 0.0050 & 0.1000 & 0.0017 & 0.0020 & 0.0024 & 0.0015 & 0.0019 & 0.0024 & 0.0006 & 0.0007 & 0.0009 \\
\hline$\sigma_{w}$ & inv. gamma & 0.0050 & 0.1000 & 0.0009 & 0.0014 & 0.0019 & 0.0009 & 0.0014 & 0.0018 & 0.0009 & 0.0014 & 0.0020 \\
\hline$\sigma_{g}$ & inv. gamma & 0.0050 & 0.1000 & 0.0024 & 0.0031 & 0.0038 & 0.0024 & 0.0031 & 0.0038 & 0.0033 & 0.0039 & 0.0044 \\
\hline$\sigma_{R}$ & inv. gamma & 0.0020 & 0.1000 & 0.0013 & 0.0014 & 0.0016 & 0.0013 & 0.0014 & 0.0016 & 0.0031 & 0.0041 & 0.0041 \\
\hline$\sigma_{\pi}$ & inv. gamma & 0.0020 & 0.1000 & 0.0005 & 0.0007 & 0.0010 & 0.0009 & 0.0014 & 0.0019 & 0.0006 & 0.0009 & 0.0012 \\
\hline \multicolumn{4}{|c|}{ Marginal likelihood } & \multicolumn{3}{|c|}{2291.2202} & \multicolumn{3}{|c|}{2290.0064} & \multicolumn{3}{|c|}{2216.9142} \\
\hline \multicolumn{4}{|c|}{ Posterior odds ratio } & \multicolumn{3}{|c|}{0.7710} & \multicolumn{3}{|c|}{0.2290} & \multicolumn{3}{|c|}{0.0000} \\
\hline
\end{tabular}

Notes: The posterior distribution is obtained using the Metropolis-Hastings algorithm. Model codes: $\mathscr{M}_{0}:$ benchmark model; $\mathscr{M}_{1}: \rho_{\pi}=0 ; \mathscr{M}_{2}: \rho=0$. The posterior odd ratios are obtained under a uniform prior on model versions. 
Table 2. Forecast Error Variance Decomposition

\begin{tabular}{|c|c|c|c|c|c|c|}
\hline & \multicolumn{6}{|c|}{ Forecast Horizon } \\
\hline & 1 & 4 & 8 & 12 & 20 & 40 \\
\hline \multicolumn{7}{|l|}{ Model $\mathscr{M}_{0}$} \\
\hline Output & 19.74 & 38.35 & 48.04 & 49.23 & 44.00 & 30.20 \\
\hline Inflation & 7.10 & 53.93 & 81.80 & 90.00 & 95.07 & 97.87 \\
\hline Wage Inflation & 7.91 & 30.17 & 57.31 & 71.18 & 82.57 & 91.18 \\
\hline Nominal Interest Rate & 1.15 & 9.24 & 34.56 & 59.00 & 81.96 & 93.91 \\
\hline Real Interest Rate & 4.51 & 19.57 & 32.19 & 38.36 & 42.01 & 42.40 \\
\hline Real Wage & 1.24 & 2.83 & 5.01 & 7.30 & 11.15 & 14.50 \\
\hline \multicolumn{7}{|l|}{ Model $\mathscr{M}_{1}$} \\
\hline Output & 1.57 & 2.89 & 3.90 & 3.97 & 3.17 & 1.85 \\
\hline Inflation & 17.97 & 47.10 & 63.25 & 71.46 & 80.26 & 88.90 \\
\hline Wage Inflation & 6.12 & 18.26 & 30.75 & 39.59 & 50.83 & 66.15 \\
\hline Nominal Interest Rate & 1.30 & 6.82 & 19.43 & 33.01 & 53.04 & 74.75 \\
\hline Real Interest Rate & 14.54 & 18.65 & 18.20 & 18.09 & 17.90 & 17.72 \\
\hline Real Wage & 0.07 & 0.04 & 0.14 & 0.25 & 0.40 & 0.52 \\
\hline \multicolumn{7}{|l|}{ Model $\mathscr{M}_{2}$} \\
\hline Output & 0.03 & 0.06 & 0.06 & 0.05 & 0.04 & 0.03 \\
\hline Inflation & 2.68 & 11.94 & 20.52 & 25.52 & 31.76 & 43.37 \\
\hline Wage Inflation & 0.44 & 4.69 & 11.43 & 16.48 & 23.69 & 37.01 \\
\hline Nominal Interest Rate & 9.72 & 36.66 & 48.69 & 52.53 & 55.63 & 63.13 \\
\hline Real Interest Rate & 0.04 & 0.05 & 0.04 & 0.04 & 0.04 & 0.03 \\
\hline Real Wage & 0.84 & 1.28 & 1.01 & 0.74 & 0.42 & 0.22 \\
\hline
\end{tabular}

Notes: Model codes: $\mathscr{M}_{0}$ : benchmark model; $\mathscr{M}_{1}: \rho_{\pi}=0 ; \mathscr{M}_{2}: \rho=0$. 
Figure 1: Data Used in Estimation
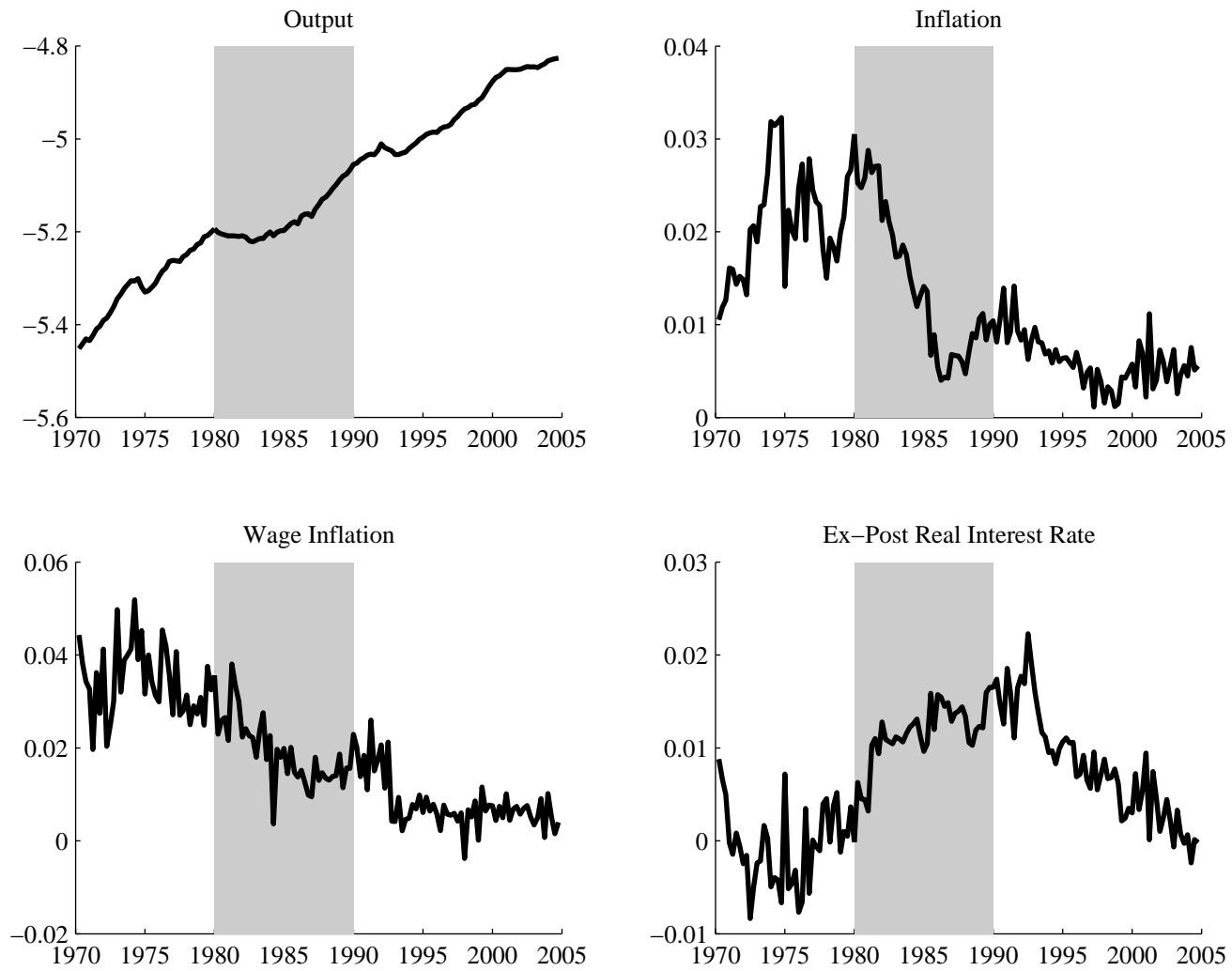

Notes: The shaded area indicates the large recession period experienced by Euro area countries in the 1980's. 

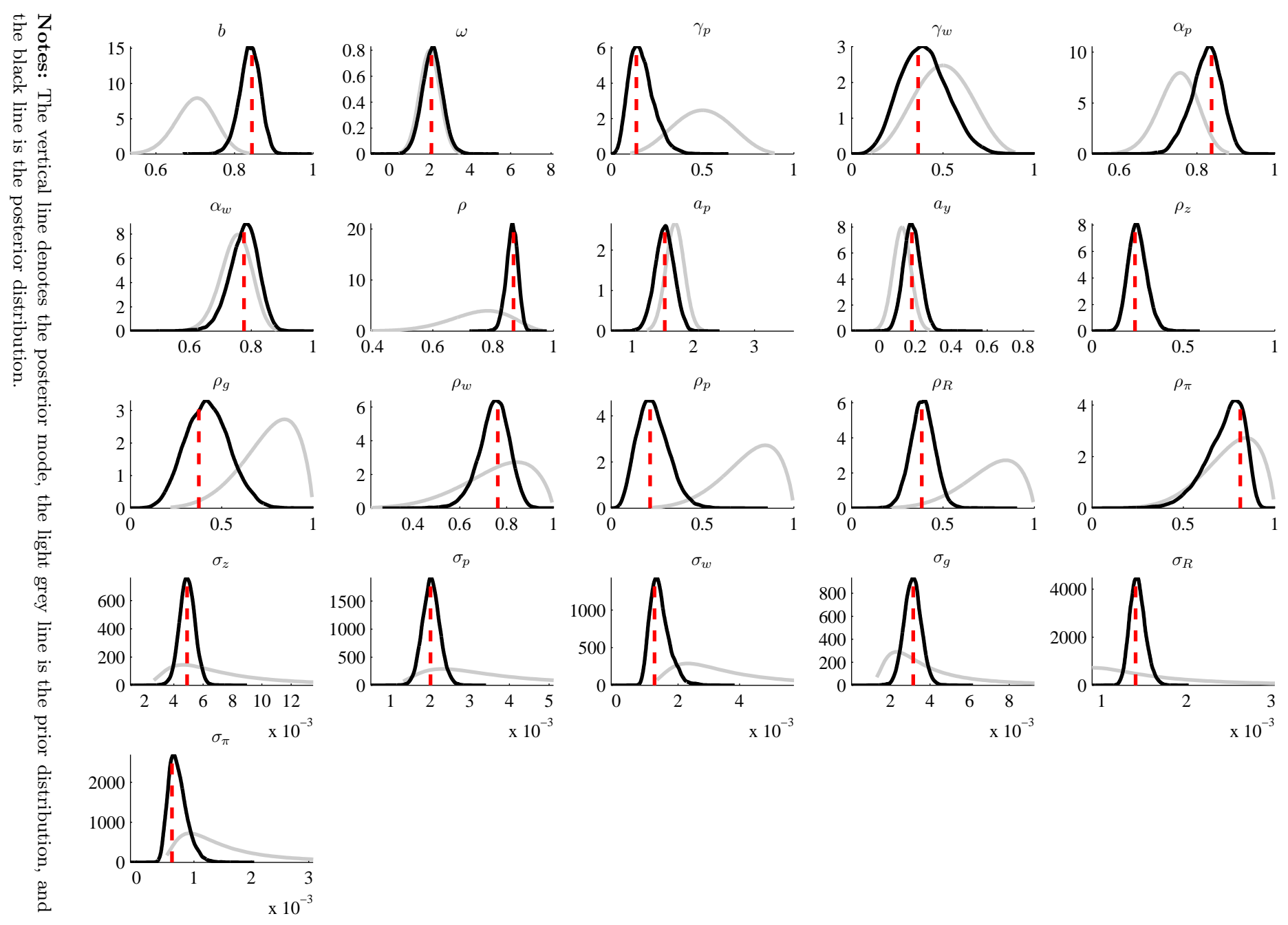

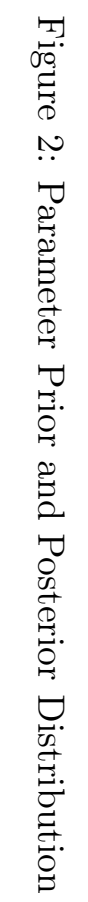
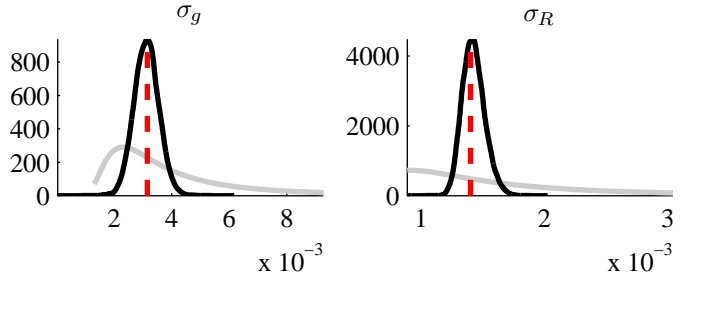
Figure 3: Inflation and Inflation Target

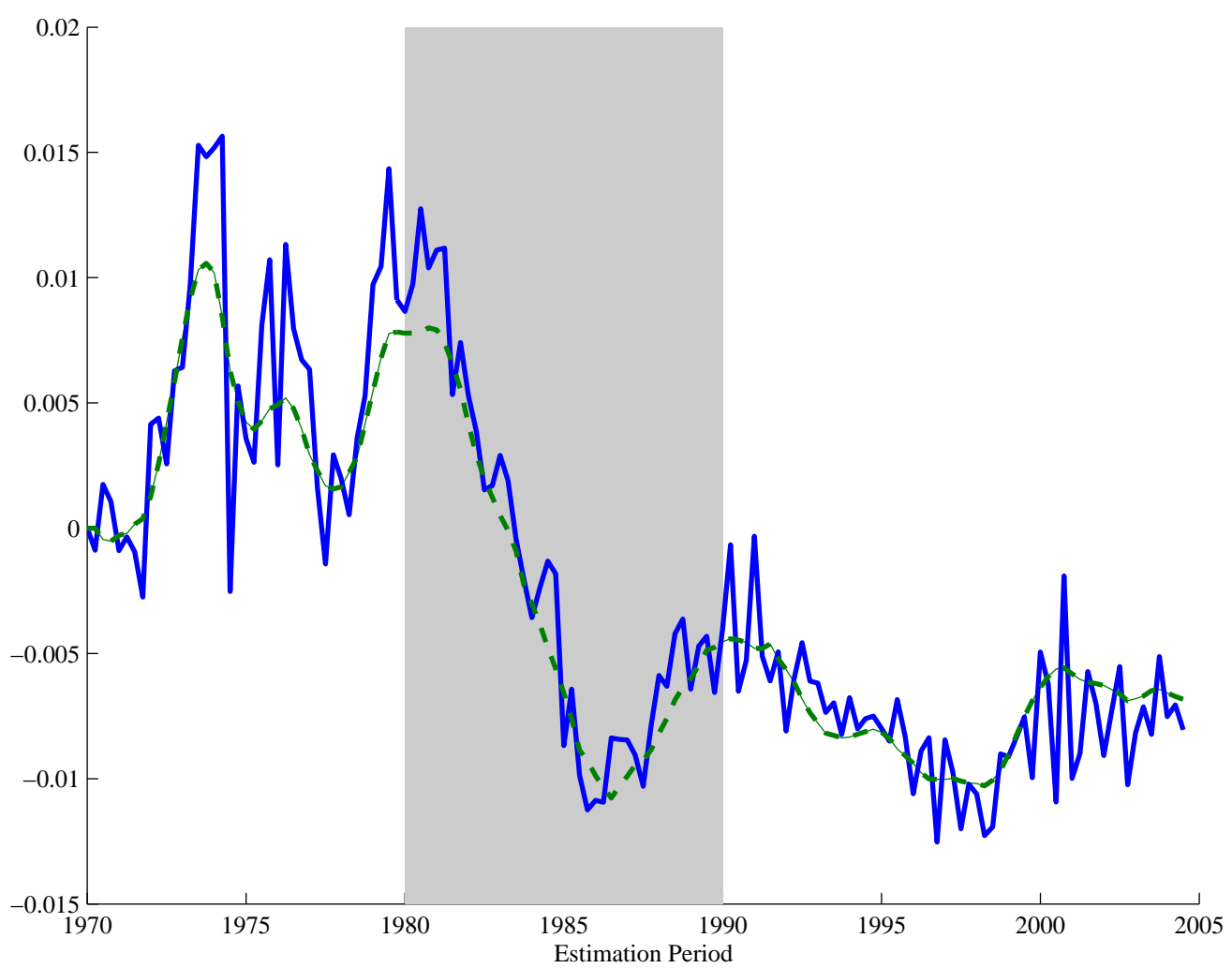

Notes: The series are demeaned. Actual inflation: solid line; inflation target: dotted line. The shaded area indicates the large recession period experienced by Euro area countries in the 1980's. 
Figure 4: Impulse Response Functions to an Inflation Target Shock
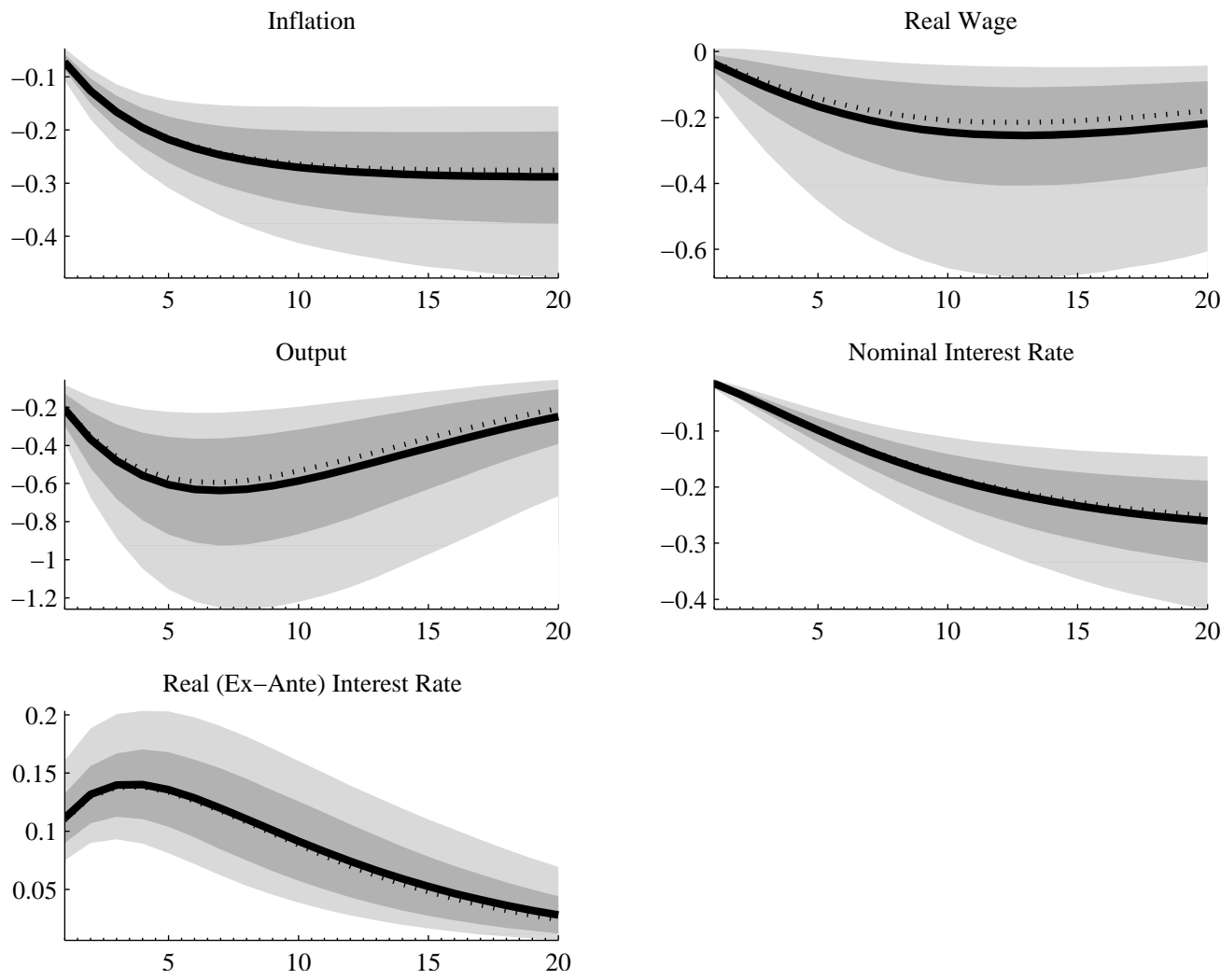

Notes: Impulse response to a one standard error \% shock. The light gray and dark gray areas correspond to the $95 \%$ and $68 \%$ HPD intervals, respectively. The thick line and the dotted line correspond to the mean and median IRFs, respectively. 
Figure 5: Impulse Response Functions to a Monetary Policy Shock
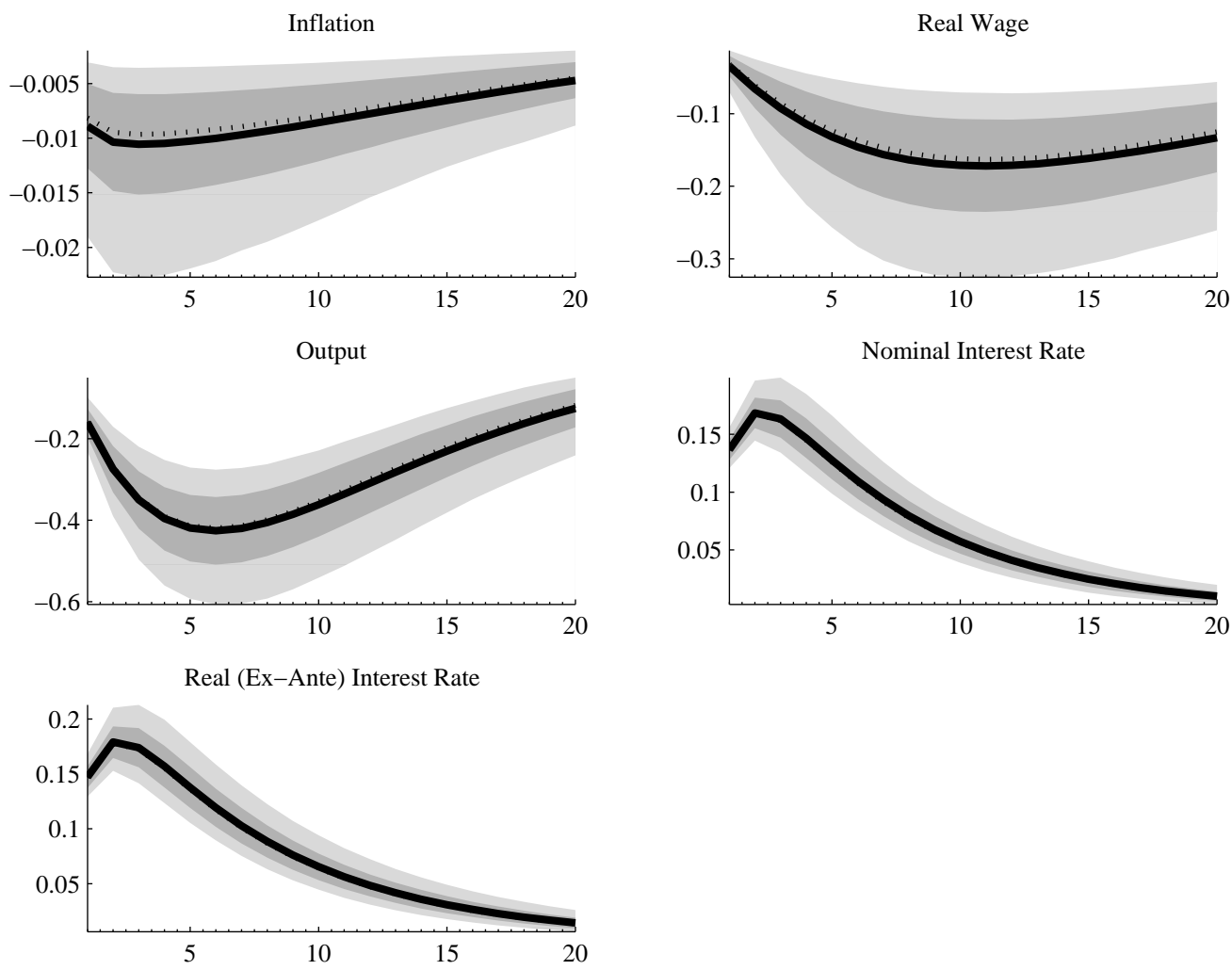

Notes: Impulse response to a one standard error \% shock. The light gray and dark gray areas correspond to the $95 \%$ and $68 \%$ HPD intervals, respectively. The thick line and the dotted line correspond to the mean and median IRFs, respectively. 
Figure 6: Counterfactual Analysis, $\hat{\pi}_{t}^{\star}=0$
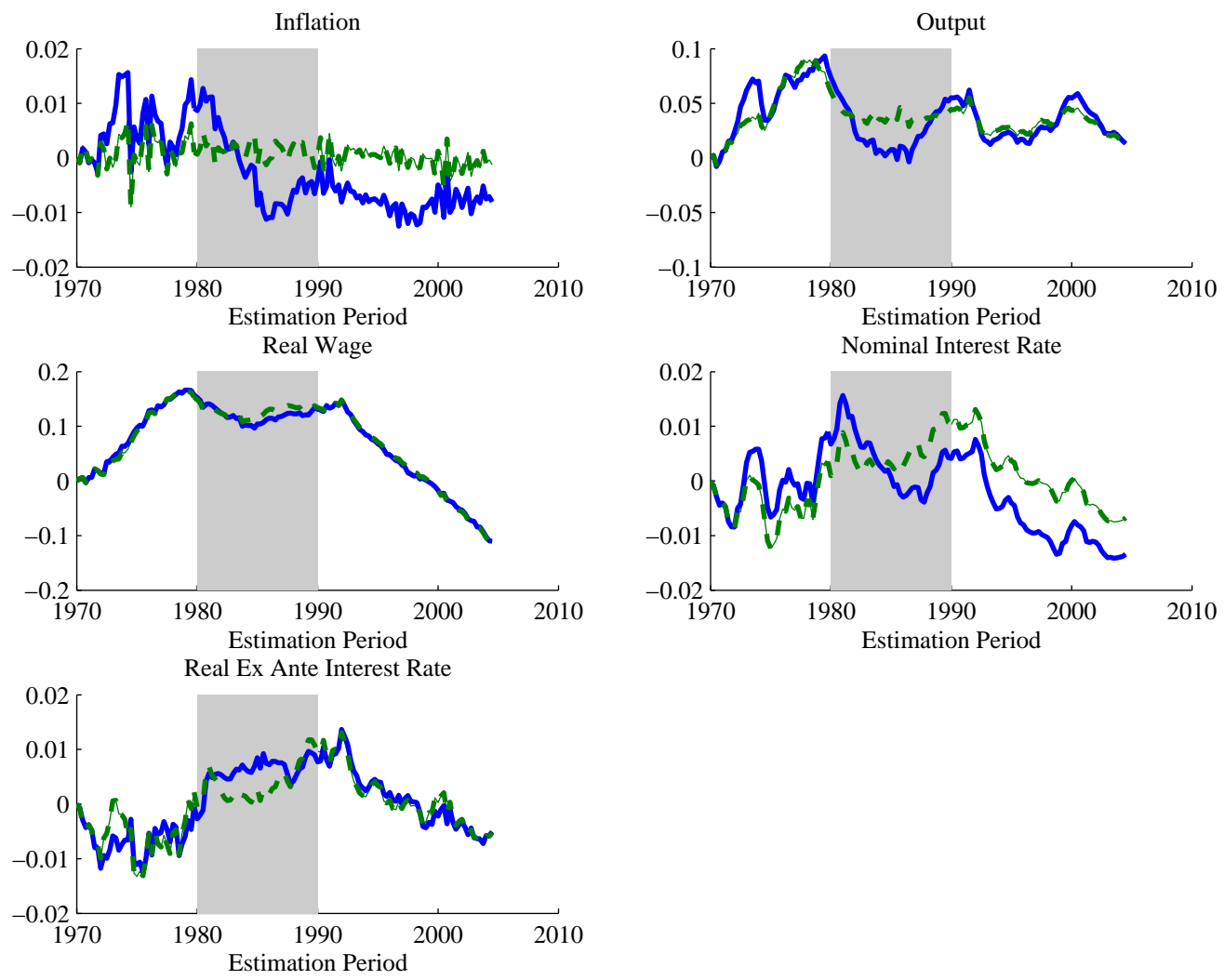

Notes: The series are demeaned. Actual variable: solid line; counterfactual variable: dotted line. The shaded area indicates the large recession period experienced by Euro area countries in the 1980's. 
Figure 7: Counterfactual IRFs
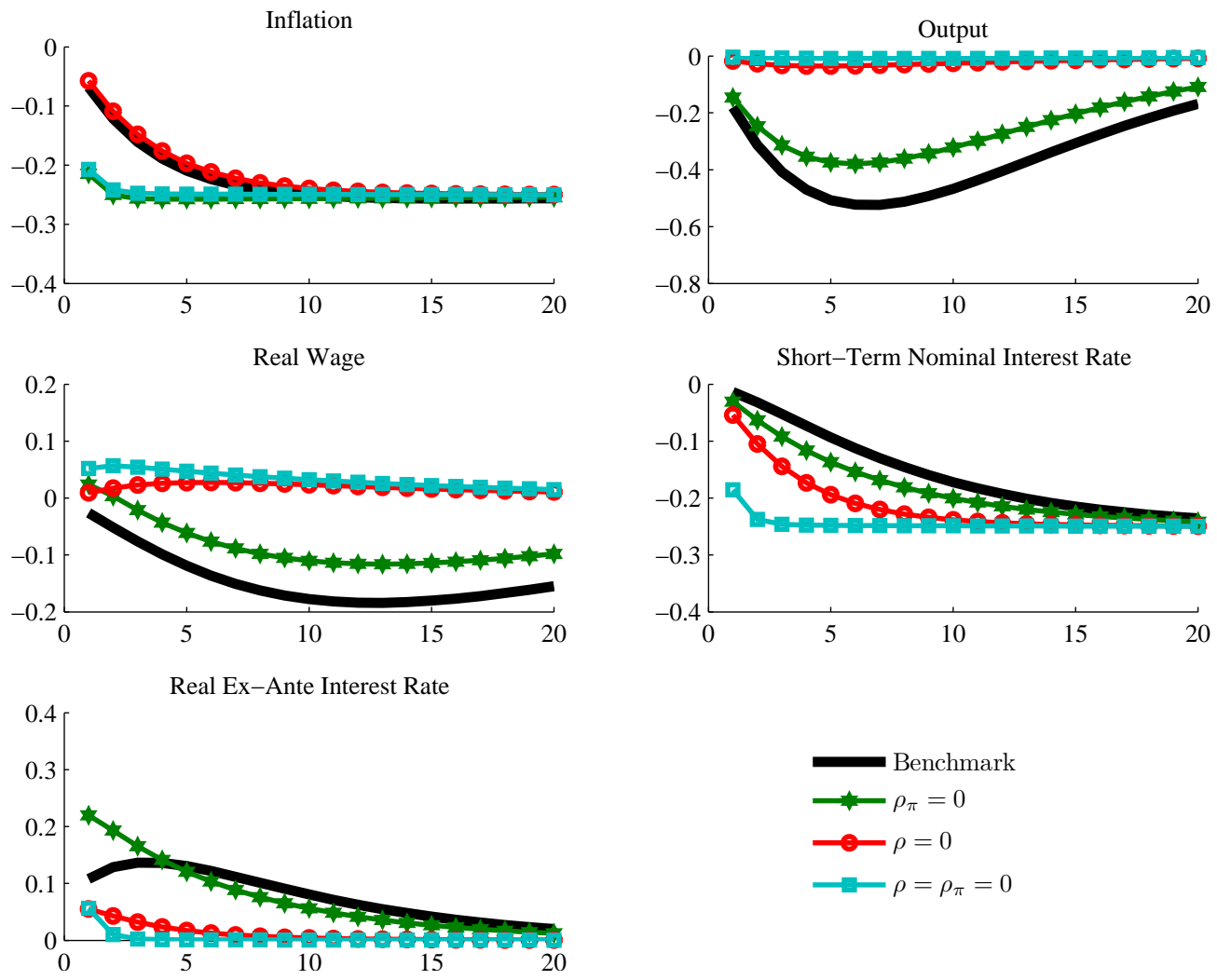

Notes: In each case, the shock is normlized so as to generate the same long-run effect on inflation. 